\title{
Borderline Intellectual Functioning and Lifetime Duration of Homelessness among Homeless Adults with Mental Illness
}

\author{
Fonctionnement intellectuel limite et durée \\ de l'itinérance chez les adultes itinérants ayant une \\ maladie mentale
}

ANNA DURBIN, PHD

Centre for Urban Health Solutions, St. Michael's Hospital

Department of Psychiatry, University of Toronto Institute for Clinical Evaluative Sciences

Toronto, ON

YONA LUNSKY, PHD

Centre for Addiction and Mental Health

Department of Psychiatry, University of Toronto

Institute for Clinical Evaluative Sciences

Toronto, ON

RI WANG, MMATH

Centre for Urban Health Solutions, St. Michael's Hospital Toronto, ON

ROSANE NISENBAUM, PHD

Centre for Urban Health Solutions and

Applied Health Research Centre

St.Michael's Hospital

Dalla Lana School of Public Health, University of Toronto

Toronto, $\mathrm{ON}$
STEPHEN W. HWANG, MD

Centre for Urban Health Solutions, St. Michael's Hospital Division of General Internal Medicine, Department of Medicine

University of Toronto

Toronto, ON

PATRICIA O'CAMPO, PHD

Centre for Urban Health Solutions, St. Michael's Hospital Dalla Lana School of Public Health, University of Toronto Toronto, ON

VICKY STERGIOPOULOS, MD

Centre for Addiction and Mental Health

Centre for Urban Health Solutions, St. Michael's Hospital Department of Psychiatry, University of Toronto Toronto, ON 
Borderline Intellectual Functioning and Lifetime Duration of Homelessness among Homeless Adults with Mental Illness

\begin{abstract}
This paper reports on the association between intellectual functioning and lifetime homelessness duration among 172 homeless adults with mental illness in Toronto, Canada. Using a standardized test of intellectual functioning, we created two groups: individuals with borderline or lower intellectual functioning (16\%) and individuals with above borderline intellectual functioning (84\%). Lifetime homelessness duration was approximately three years longer, or almost twice as long, for individuals with borderline or lower intellectual functioning. Implementing more systematic strategies for identifying and supporting individuals with cognitive impairments may hasten transitions out of homelessness for this population. Brief intellectual functioning assessment tools are available.
\end{abstract}

\title{
Résumé
}

Cet article porte sur les liens entre le fonctionnement intellectuel et la durée de l'itinérance dans le cas de 172 adultes itinérants ayant une maladie mentale à Toronto, Canada. Nous avons créé deux groupes au moyen d'un test normalisé portant sur le fonctionnement intellectuel. Ces deux groupes sont : les personnes qui présentent un fonctionnement intellectuel limite ou moins élevé (16\%) et les personnes qui présentent un fonctionnement intellectuel plus élevé que l'état limite (84\%). La durée de l'itinérance était approximativement trois ans plus longue, soit près de deux fois plus importante, chez les personnes ayant un fonctionnement intellectuel limite ou moins élevé. La mise en place de stratégies plus systématiques pour repérer et soutenir les personnes qui présentent des déficits cognitifs pourrait accélérer leur sortie de l'itinérance. Il existe des outils pratiques pour évaluer le fonctionnement intellectuel.

\section{Introduction}

Compared to the general population, homeless individuals have more physical, mental health problems, and cognitive deficits (Hwang 2001; Nishio et al. 2015; Rohde et al. 1999; Stergiopoulos et al. 2014; Stergiopoulos et al. 2015). These challenges can be exacerbated during prolonged periods of homelessness, for example, due to lengthy exposure to weather, infections, drugs and violence (Blair and Spreen 1989).

Homeless programs do not typically evaluate participants' intellectual functioning or provide supports to people with these deficits (Van Straaten et al. 2014), potentially prolonging homelessness by not providing supports for deficits in intellectual functioning. Only two small studies have examined the relationship between duration of homelessness and intellectual functioning, yielding inconsistent findings. One Japanese study of 18 homeless individuals (Nishio et al. 2015) reported that intellectual disability was associated with longer durations of homelessness, while a study (Rohde et al. 1999) of 50 homeless adolescents in the US found no relationship. The paucity of research and study limitations 
accentuate the need for more studies in this area to inform delivery of more effective supports and interventions.

The aim of this study is to: 1) describe the premorbid intellectual functioning level, duration of homelessness, as well as sociodemographic and clinical characteristics of 172 English-speaking homeless adults with mental illness in Toronto, ON, and 2) assess whether premorbid borderline or lower intellectual functioning is associated with homelessness duration.

\section{Method}

\section{Sample and Setting}

The sample included 172 individuals from a larger study of 575 homeless adults with mental illness who participated in the Toronto site of the Canadian At Home/Chez Soi randomized trial between 2009 and 2013. Nearly two-thirds of participants had mood disorders, and over one-half had substance-related problems (Stergiopoulos et al. 2014). This trial evaluated the effects of Housing First, an approach that provides participants with access to permanent independent housing in conjunction with client-centred treatment and mental health support services. In this approach housing is not contingent on acceptance of treatment or demonstration of sobriety. The participants receiving Housing First were compared to a control group that received no specific intervention but had access to locally available services (e.g., emergency shelters, case management) (Stergiopoulos et al. 2014). Participants were referred to the At Home/Chez Soi study from community agencies such as shelters, drop-in centres, street outreach teams, in-patient programs, or criminal justice programs, or identified by interviewers. Eligible participants had to be absolutely homeless, or precariously housed with episodes of absolute homelessness in the past year (see Appendix 1 for definitions at www.longwoods.com/content/25687) (Goering et al. 2011). Additional inclusion criteria were being at least 18 years old and having a serious mental disorder. More study information is provided in detail elsewhere (Goering et al. 2011; Stergiopoulos et al. 2014).

Of the 575 Toronto participants, 414 were included in an additional two-year follow-up, but only 364 of these individuals completed the extended study. Of these individuals, 189 (51.9\%) were eligible to take the intellectual functioning test because they spoke English, did not have visual impairments and were available for face-to-face interviews. Seventeen potential participants (4.7\%) refused or had missing data, leading to a final sample of 172 participants with an intellectual functioning assessment. There were no significant differences between those included $(n=172)$ and those in the total Toronto sample but not included in the current analysis $(n=403)$ with respect to age and gender.

The At Home/Chez Soi study was approved by institutional research ethics boards at St. Michael's Hospital and was registered with the International Standard Randomized Control Trial Number (ISRCTN 42520374). 
Borderline Intellectual Functioning and Lifetime Duration of Homelessness among

Homeless Adults with Mental Illness

\section{Variables}

Premorbid rather than current intellectual functioning was assessed to avoid confounding by illness severity. We measured premorbid intellectual functioning using the Revised New Adult Reading Test (NART/NART-R) that displayed 61 words that do not follow regular grapheme-phoneme rules that participants were asked to read and pronounce (Blair and Spreen 1989; Strauss et al. 2006). Similar to prior research (Hassiotis et al. 2008), the verbal intelligence NART-R score was converted to an IQ score (Blair and Spreen 1989). Borderline intellectual functioning occurs when a person has below average cognitive ability, indicated by having an IQ in the 70-84 range. A more severe intellectual impairment is consistent with a diagnosis of intellectual disability, defined by having an IQ less than 70 . Intellectual disabilities originate before age 18 and are characterized by lifelong limitations in cognitive and adaptive functioning that impact on activities of daily living. Due to the small sample size and NART-R limitations, we compared the group of participants with borderline or lower intellectual functioning (IQ score $<85$ ) to those with above borderline intellectual functioning (IQ score of $85+$ ).

The outcome, lifetime duration of homelessness (in years), was measured at the baseline study visit when participants were asked: "In your lifetime, what is the total amount of time you have been homeless?" Other variables examined are listed in Table 1 available at www.longwoods.com/content/25687.

\section{STATISTICAL ANALYSIS}

Intellectual functioning groups were compared with respect to sociodemographic factors, mental and physical health using the two-sample t-test or Fisher's exact test. Bivariate comparisons of homelessness duration between groups were made with the Mann-Whitney $\mathrm{U}$ test for the whole sample ( $\mathrm{n}=172$, primary analysis). To address concerns that immigrants may have worse English proficiency, affecting their performance on the NART-R, we also ran a sensitivity bivariate analysis on the sample excluding immigrants ( $\mathrm{n}=131$, sensitivity analysis). A multivariable linear regression model assessed the association between intellectual functioning and lifetime duration of homelessness. Covariates (Table 1) were included in the adjusted model if they were conceptually relevant or statistically significant in the bivariate analysis.

Data analyses were conducted using R (version 3.4.0). All statistical tests were two-tailed and statistical significance was defined as $p$-values less than 0.05 .

\section{Results}

Of the 172 study participants, 144 (83.7\%) had premorbid IQ scores above the borderline intellectual functioning cut-off, and $28(16.3 \%)$ had scores in the borderline premorbid IQ range or below. Compared to the former group, individuals in the borderline or lower intellectual functioning group were more likely to be immigrants ( $46.4 \%$ versus $19.4 \%, p=0.006$ ) and to have completed at most some high school (75.0\% versus $45.8 \%, p=0.007)$. Groups 
were similar with respect to age, gender, ethnicity, receipt of disability income support, mental health functioning, any mental health or addictions disorder or symptom severity, arrests, or community provider visits (data not shown).

In the primary bivariate analysis of the entire sample, lifetime duration of homelessness was longer for the borderline or lower intellectual functioning group (median 6.0 years vs. 3.2 years, $p=0.038$, Table 1 ). Results were similar in the sensitivity analysis that excluded immigrants (median 7.0 years [IQR 5.2-11.6] vs. 4.5 [IQR 1.8-9.0], p=0.02). Similarly, in the multivariable analysis, membership in the borderline or lower intellectual functioning group was associated with an average longer homelessness duration of approximately 3.0 years $(p<0.01$, Table 1$)$. Other variables associated with increased average homelessness duration in the multivariable analysis were male gender $(p<0.01)$, and increased age $(p<0.01)$. Ethnoracial, compared to White ethnicity, was associated with decreased average homeless duration $(p=0.03)$.

\section{Discussion}

A prevalence of borderline or lower intellectual functioning of $16.3 \%$ in our setting is consistent with findings in other jurisdictions, with reported prevalence rates ranging from $6.0 \%$ to 37.5\%. Moreover, international studies have noted that evaluations of participants' intellectual functioning are generally absent from homeless programs (Van Straaten et al. 2014). Since the present study was done in a setting with universal health insurance that recently invested considerable funds into community mental health (SEEI Coordinating Centre 2009), the finding that people with mental illness in the borderline premorbid IQ range or below were homeless for about three years longer (about twice as long) as other homeless individuals with mental illness may even be more pronounced in other settings where health and social supports are even less accessible.

These findings suggest that it may be harder for individuals with lower intellectual functioning to exit homelessness, highlighting their unique and complex support needs, such as requiring help to understand information and complete routine tasks (Nishio et al. 2015). Furthermore, identifying these individuals may be challenging (Lougheed and Farrell 2013) as impairments may not be obvious to staff with no specific training in this area (Nishio et al. 2015). Brief cognitive assessment tools can be integrated into homeless services to identify these clients and support more appropriate person-centred service planning (Lougheed and Farrell 2013).

\section{Limitations}

Premorbid IQ scores on the NART-R could not be below 74 (a floor effect) so we could not separate people with an intellectual disability from those with borderline intellectual functioning. In addition, we did not evaluate intellectual delays that developed after childhood, or estimate current full-scale IQ or verbal IQ. However, NART-R scores correlate with full-scale IQ and verbal IQ (Blair and Spreen 1989; Strauss et al. 2006). Also, since 


\section{Borderline Intellectual Functioning and Lifetime Duration of Homelessness among}

Homeless Adults with Mental Illness

data were ascertained via self-report, there may have been inaccuracies in the information reported, especially for individuals in the borderline or lower intellectual functioning group. Study strengths are a moderately large and well-characterized sample of homeless adults with mental illness, and adding to a very small body of literature on intellectual functioning and duration of homelessness. Prior studies in this area had few participants (Cotman and Sandman 1997; Oakes and Davies 2008; Rohde et. 1999) or did not examine homelessness duration (Van Straaten et al. 2014).

\section{Conclusion}

Present findings support existing calls (Durbin et al. 2018; Lougheed and Farrell 2013) to consider screening for intellectual functioning in programs that serve homeless individuals, and tailor interventions to better support this disadvantaged population. The prevalence of intellectual disabilities compared to borderline intellectual functioning among homeless people, and the experience of these groups with respect to homelessness and barriers to getting housed, should be examined in future work.

\section{Acknowledgements}

This research has been made possible through a financial contribution from Health Canada and funded by the Mental Health Commission of Canada. The views expressed herein solely represent the authors'.

Correspondence may be directed to: Anna Durbin, $\mathrm{PhD}$, Centre for Urban Health Solutions, St. Michael's Hospital, Toronto, ON; e-mail:durbinan@smb.ca.

\section{References}

Blair, J.R. and O. Spreen. 1989. "Predicting Premorbid IQ: A Revision of the National Adult Reading Test." Clinical Neuropsychologist 3(2): 129-36. Retrieved November 15, 2017. <http://www.tandfonline.com/doi/ abs/10.1080/13854048908403285>.

Cotman, A. and C. Sandman. 1997. "Cognitive Deficits and Their Remediation in the Homeless." Journal of Cognitive Rehabilitation 15: 16-24.

Durbin, A., B. Isaacs, D. Mauer-Vakil, J. Connelly, L. Steer, S. Roy and V. Stergiopoulos 2018. "Intellectual Disability and Homelessness: A Synthesis of the Literature and Discussion of How Supportive Housing Can Support Wellness for People with Intellectual Disability." Current Developmental Disorders Reports 5(3): 125 31. doi.org/10.1007/s40474-018-0141-6.

Goering, P.N., D.L. Streiner, C. Adair, T. Aubry, J. Barker, J. Distasio et al. 2011. “The At Home/Chez Soi Trial Protocol: A Pragmatic, Multi-Site, Randomised Controlled Trial of a Housing First Intervention for Homeless Individuals with Mental Illness in Five Canadian Cities." BMJ Open 1(2): e000323. doi: 10.1136/ bmjopen-2011-000323.

Griffin, S.L., M.R. Mindt, E.J. Rankin, A.J. Ritchie and J.G. Scott. 2002. “Estimating Premorbid Intelligence: Comparison of Traditional and Contemporary Methods across the Intelligence Continuum." Archives Clinical Neuropsychology 17: 497-507.

Hassiotis, A., A. Strydom, I. Hall, A. Ali, G. Lawrence-Smith, H. Meltzer et al. 2008. "Psychiatric Morbidity and Social Functioning among Adults with Borderline Intelligence Living in Private Households." Journal of Intellectual Disability Research 52: 95-106. 
Hwang, S.W. 2001. "Homelessness and Health." Canadian Medical Association Journal 164: 229-33.

Lougheed, D.C. and S. Farrell. 2013. “The Challenge of a 'Triple Diagnosis': Identifying and Serving Homeless Canadian Adults with a Dual Diagnosis." Journal of Policy and Practice in Intellectual Disabilities 10: 230-35.

Nishio, A., M. Yamamoto, H. Ueki, T. Watanabe, K. Matsuura, O. Tamura et al. 2015. "Prevalence of Mental Illness, Intellectual Disability, and Developmental Disability among Homeless People in Nagoya, Japan: A Case Series Study." Psychiatry and Clinical Neurosciences 69: 534-42.

Oakes, P.M. and R.C. Davies. 2008. "Intellectual Disability in Homeless Adults." Journal of Intellectual Disability Research 12: 325-34.

Rohde, P., J. Noell and L. Ochs. 1999. "IQ Scores among Homeless Older Adolescents: Characteristics of Intellectual Performance and Associations with Psychosocial Functioning." Journal of Adolescence 22: 319-28.

SEEI Coordinating Centre. 2009. "Moving in the Right Direction: SEEI Final Report." Health Systems Research and Consulting Unit, Centre for Addiction and Mental Health. Retrieved December 17, 2017. http://ontario.cmha.ca/wp-content/uploads/2016/08/seei_final_report_cmha_ontario_March2003.pdf.

Stergiopoulos, V., A. Cusi, T. Bekele, A. Skosireva, E. Latimer, C. Schütz et al. 2015. "Neurocognitive Impairment in a Large Sample of Homeless Adults with Mental Illness." Acta Psychiatrica Scandinavica 131: 256-68.

Stergiopoulos, V., P. O’Campo, S. Hwang, A. Gozdzik, J. Jeyaratnam et al. 2014. “At Home/Chez Soi Project: Toronto Site Final Report." Calgary, AB: Mental Health Commission of Canada. Retrieved December 19, 2017. https:/www.mentalhealthcommission.ca/sites/default/files/At\%252520Home\%252520Report\%252520Toront o\%252520ENG_0.pdf.

Strauss, E., E. Sherman and O. Spreen. 2006. "A Compendium of Neuropsychological Tests: Administration, Norms, and Commentary." Oxford University Press.

Van Straaten, B., C.T.M. Schrijvers, J. Van Der Laan, S.N. Boersma, G. Rodenburg, J.R.L.M. Wolf et al. 2014. "Intellectual Disability among Dutch Homeless People: Prevalence and Related Psychosocial Problems." PLoS One 9(1): e86112.

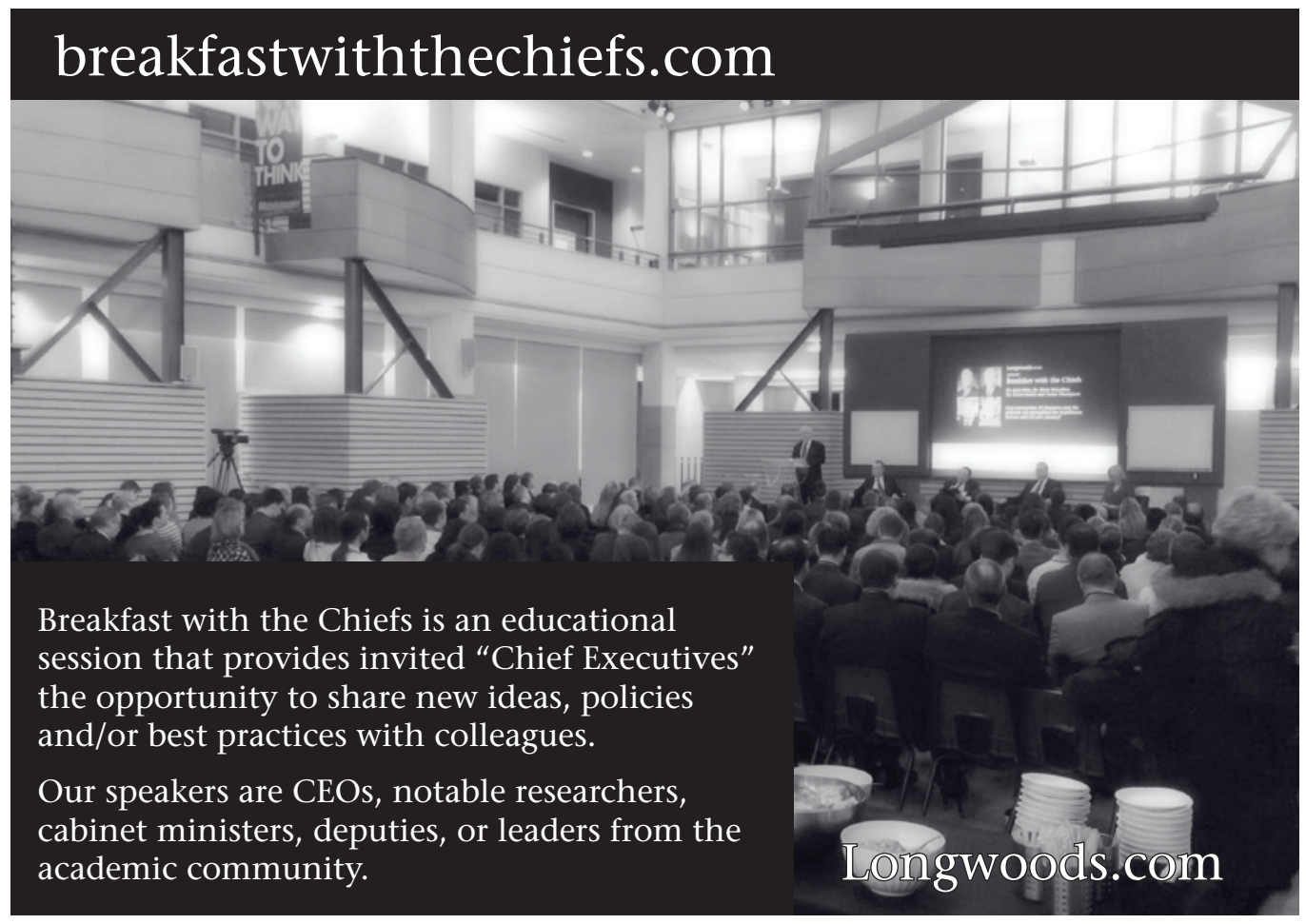

